\title{
Sheep Lung Adenocarcinoma
}

National Cancer Institute

\section{Source}

National Cancer Institute. Sheep Lung Adenocarcinoma. NCI Thesaurus. Code C147532.

Adenocarcinoma arising from the lung of a sheep. 